\title{
AN APPLICATION OF A SUBORDINATION CHAIN
}

\author{
SUKHJIT SINGH and SUSHMA GUPTA
}

\author{
Received 12 April 2002
}

Let $K$ denote the class of functions $g(z)=z+a_{2} z^{2}+\cdots$ which are regular and univalently convex in the unit disc $E$. In the present note, we prove that if $f$ is regular in $E, f(0)=0$, then for $g \in K, f(z)+\alpha z f^{\prime}(z) \prec g(z)+\alpha z g^{\prime}(z)$ in $E$ implies that $f(z) \prec g(z)$ in $E$, where $\alpha>0$ is a real number and the symbol " $\prec$ " stands for subordination.

2000 Mathematics Subject Classification: 30C45, 30C50.

1. Introduction. Let $S$ denote the class of functions

$$
f(z)=z+\sum_{n=2}^{\infty} a_{n} z^{n}
$$

which are regular and univalent in the unit disc $E=\{z:|z|<1\}$. A function $f \in S$ is said to be convex of order $\beta, 0 \leq \beta<1$, if and only if

$$
\operatorname{Re}\left[1+\frac{z f^{\prime \prime}(z)}{f^{\prime}(z)}\right]>\beta, \quad z \in E .
$$

For a given $\beta, 0 \leq \beta<1$, let $K(\beta)$ denote the subclass of $S$ consisting of convex functions of order $\beta$ and let $K=K(0)$ be the usual class of convex functions.

A function $f$ given by (1.1) is said to be close-to-convex in $E$ if $f$ is regular in $E$ and if there exists a function $g \in K$ such that

$$
\operatorname{Re}\left[\frac{f^{\prime}(z)}{g^{\prime}(z)}\right]>0, \quad z \in E .
$$

It is well known that if a function is close-to-convex in $E$, then it is univalent in $E$.

Suppose that $f$ and $g$ are regular in $|z|<\rho$ and $f(0)=g(0)$. In addition, suppose that $g$ is also univalent in $|z|<\rho$. We say that $f$ is subordinate to $g$ in $|z|<\rho$ (in symbols, $f(z) g \prec(z)$ in $|z|<\rho)$ if $f(|z|<\rho) \subset g(|z|<\rho)$.

In 1947, Robinson [4] proved that if $g(z)+z g^{\prime}(z)$ is in $S$ and $f(z)+z f^{\prime}(z) \prec$ $g(z)+z g^{\prime}(z)$ in $|z|<1$, then $f(z) \prec g(z)$ at least in $|z|<r_{0}=1 / 5$. S. Singh and R. Singh [6], in 1981, increased the constant $r_{0}$ to $2-\sqrt{3}=0.268 \ldots$ Subsequently, in 1984, Miller et al. [2] further increased this constant to $4-\sqrt{13}=$ $0.3944 \ldots$. 
Recently, R. Singh and S. Singh [5] pursued the problem initiated by Robinson when $g \in K(\beta)$. In fact, they considered the cases when $\beta=0$ and $\beta=1 / 2$ and proved the following results.

THEOREM 1.1. Let $f$ be regular in $E$ with $f(0)=0$ and let $g \in K$. Suppose that

$$
f(z)+z f^{\prime}(z) \prec g(z)+z g^{\prime}(z)
$$

in E. Then,

$$
f(z) \prec g(z)
$$

at least in $|z|<r_{0}$, where $r_{0}=\sqrt{5} / 3=0.745 \ldots$

THEOREM 1.2. Let $f$ be regular in $E, f(0)=0$, and let $g \in K(1 / 2)$. Then

$$
f(z)+z f^{\prime}(z) \prec g(z)+z g^{\prime}(z)
$$

in E implies that

$$
f(z) \prec g(z)
$$

at least in $|z|<r_{1}$, where $r_{1}=((51-24 \sqrt{2}) / 23)^{1 / 2}=0.8612 \ldots$

In the present note, we consider the subordination $f(z)+\alpha z f^{\prime}(z) \prec g(z)+$ $\alpha z g^{\prime}(z)$ in $|z|<1, g \in K$ and $\alpha>0$, and show that the subordination $f(z) \prec$ $g(z)$ holds in the entire disc $|z|<1$ and does not depend upon the order of convexity of $g$ as claimed by R. Singh and S. Singh in [5].

2. Preliminaries. We will need the following definition and results to prove our theorem.

DEFINITION 2.1. A function $L(z, t), z \in E$ and $t \geq 0$, is said to be a subordination chain if $L(\cdot, t)$ is analytic and univalent in $E$ for all $t \geq 0, L(z, \cdot)$ is continuously differentiable on $[0, \infty)$ for all $z$ in $E$, and $L\left(z, t_{1}\right) \prec L\left(z, t_{2}\right)$ for $0 \leq t_{1} \leq t_{2}$.

LEMMA 2.2 [3, page 159]. The function $L(z, t)=a_{1}(t) z+\cdots$, with $a_{1}(t) \neq 0$ for $t \geq 0$ and $\lim _{t \rightarrow \infty}\left|a_{1}(t)\right|=\infty$, is a subordination chain if and only if

$$
\operatorname{Re}\left[z \frac{\partial L / \partial z}{\partial L / \partial t}\right]>0, \quad z \in E, t \geq 0 .
$$

LEMMA 2.3. Let $p$ be analytic in $E$ and $q$ analytic and univalent in $\bar{E}$ except for points where $\lim _{z \rightarrow \varsigma} p(z)=\infty$ with $p(0)=q(0)$. If $p$ is not subordinate to $q$, then there is a point $z_{0} \in E$ and $\zeta_{0} \in \partial E$ (boundary of $E$ ) such that $p(|z|<$ $\left.\left|z_{0}\right|\right) \subset q(E), p\left(z_{0}\right)=q\left(\zeta_{0}\right)$, and $z_{0} p^{\prime}\left(z_{0}\right)=m \zeta_{0} q^{\prime}\left(\zeta_{0}\right)$ for $m \geq 1$.

Lemma 2.3 is due to Miller and Mocanu [1]. 


\section{Main theorem}

THEOREM 3.1. Let $f$ be regular in $E$ with $f(0)=0$ and let $g \in K$. For any real number $\alpha, \alpha>0$, suppose that

$$
f(z)+\alpha z f^{\prime}(z) \prec g(z)+\alpha z g^{\prime}(z)
$$

in E. Then,

$$
f(z) \prec g(z)
$$

in $E$.

Proof. First, we observe that $g(z)+\alpha z g^{\prime}(z)=h(z)$, say, is close-to-convex and hence univalent in $E$ whenever $g \in K$. Without any loss of generality, we can assume that $g$ is regular and univalent in the closed disc $\bar{E}$. If possible, suppose that $f(z)$ is not subordinate to $g(z)$ whenever (3.1) holds. Then by Lemma 2.3, there exist points $z_{0} \in E, \zeta_{0} \in \partial E$, and $m \geq 1$ such that $f\left(|z|<\left|z_{0}\right|\right) \subset g(E)$, $f\left(z_{0}\right)=g\left(\zeta_{0}\right)$, and $z_{0} f^{\prime}\left(z_{0}\right)=m \zeta_{0} g^{\prime}\left(\zeta_{0}\right)$. This gives

$$
f\left(z_{0}\right)+\alpha z_{0} f^{\prime}\left(z_{0}\right)=g\left(\zeta_{0}\right)+m \alpha \zeta_{0} g^{\prime}\left(\zeta_{0}\right) .
$$

Define a function

$$
L(z, t)=h(z)+\alpha t z g^{\prime}(z)=a_{1}(t) z+\cdots .
$$

Since $h(z)$ and $z g^{\prime}(z)$ are analytic in $E, L(z, t)$ is also analytic in $E$ for all $t \geq 0$, and is continuously differentiable on $[0, \infty)$ for all $z \in E$. Now, from (3.4), we get

$$
a_{1}(t)=\frac{\partial L}{\partial z}(0, t)=1+\alpha(1+t) \neq 0
$$

for all $t \geq 0$ and $\alpha>0$. Also

$$
\lim _{t \rightarrow \infty}\left|a_{1}(t)\right|=\infty .
$$

As $g \in K$, a simple calculation yields

$$
\operatorname{Re}\left[z \frac{\partial L / \partial z}{\partial L / \partial t}\right]=\operatorname{Re}\left[\frac{1}{\alpha}+(1+t)\left(1+\frac{z g^{\prime \prime}(z)}{g^{\prime}(z)}\right)\right]>0
$$

for $z \in E, t \geq 0$, and $\alpha>0$. Hence, by Lemma 2.2, $L(z, t)$ is a subordination chain. Therefore, in view of Definition 2.1, we have $L\left(z, t_{1}\right) \prec L\left(z, t_{2}\right)$ for $0 \leq$ $t_{1} \leq t_{2}$. Since, from (3.4), $L(z, 0)=h(z)$, we deduce that

$$
L\left(\zeta_{0}, t\right) \notin h(E)
$$

for $\left|\zeta_{0}\right|=1$ and $t \geq 0$. 
Now, in view of (3.4) and (3.3), we can write

$$
f\left(z_{0}\right)+\alpha z_{0} f^{\prime}\left(z_{0}\right)=L\left(\zeta_{0}, m-1\right),
$$

where $z_{0} \in E,\left|\zeta_{0}\right|=1$, and $m \geq 1$. Formula (3.9), when combined with (3.8), contradicts (3.1). Hence, we must have $f(z) \prec g(z)$ in $E$. This completes the proof of our theorem.

Letting $\alpha$ approach infinity, we arrive at the following well-known result of Suffridge [7].

COROLlarY 3.2. Let $f$ be regular in $E$ with $f(0)=0$ and let $g \in K$. If $z f^{\prime}(z) \prec z g^{\prime}(z)$ in $E$, then $f(z) \prec g(z)$ in $E$.

We now present some interesting examples choosing $g$ as some distinguished member of the class $K$.

Let $f$ be regular in $E, f(0)=0$, and let $\alpha>0$. Then

(a) $f(z)+\alpha z f^{\prime}(z) \prec z /(1-z)+\alpha z /(1-z)^{2}$ in $E \Rightarrow f(z) \prec z /(1-z)$ in $E$;

(b) $f(z)+\alpha z f^{\prime}(z) \prec e^{z}(1+\alpha z)-1$ in $E \Rightarrow f(z) \prec e^{z}-1$ in $E$;

(c) $f(z)+\alpha z f^{\prime}(z) \prec-\log (1-z)+\alpha z /(1-z)$ in $E \Rightarrow f(z) \prec-\log (1-z)$ in $E$.

Note that the function $-\log (1-z)$ is convex of order $1 / 2$ in $E$.

\section{REFERENCES}

[1] S. S. Miller and P. T. Mocanu, Differential subordinations and univalent functions, Michigan Math. J. 28 (1981), no. 2, 157-171.

[2] S. S. Miller, P. T. Mocanu, and M. O. Reade, Subordination-preserving integral operators, Trans. Amer. Math. Soc. 283 (1984), no. 2, 605-615.

[3] Ch. Pommerenke, Univalent Functions, Studia Mathematica/Mathematische Lehrbücher, vol. 25, Vandenhoeck \& Ruprecht, Göttingen, 1975.

[4] R. M. Robinson, Univalent majorants, Trans. Amer. Math. Soc. 61 (1947), 1-35.

[5] R. Singh and S. Singh, Subordination by convex functions, Int. J. Math. Math. Sci. 24 (2000), no. 8, 563-568.

[6] S. Singh and R. Singh, Subordination by univalent functions, Proc. Amer. Math. Soc. 82 (1981), no. 1, 39-47.

[7] T. J. Suffridge, Some remarks on convex maps of the unit disk, Duke Math. J. 37 (1970), 775-777.

Sukhjit Singh: Department of Mathematics, Sant Longowal Institute of Engineering and Technology, Longowal-148, 106 Punjab, India

E-mail address: sukhjit_d@yahoo.com

Sushma Gupta: Department of Mathematics, Sant Longowal Institute of Engineering and Technology, Longowal-148, 106 Punjab, India

E-mail address: sushmagupta1@yahoo.com 


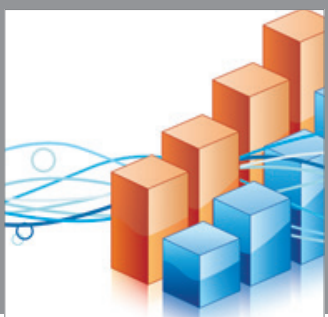

Advances in

Operations Research

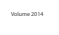

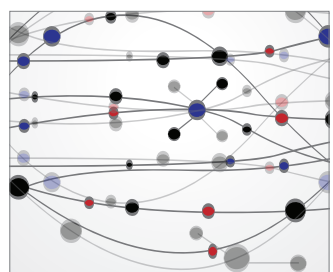

\section{The Scientific} World Journal
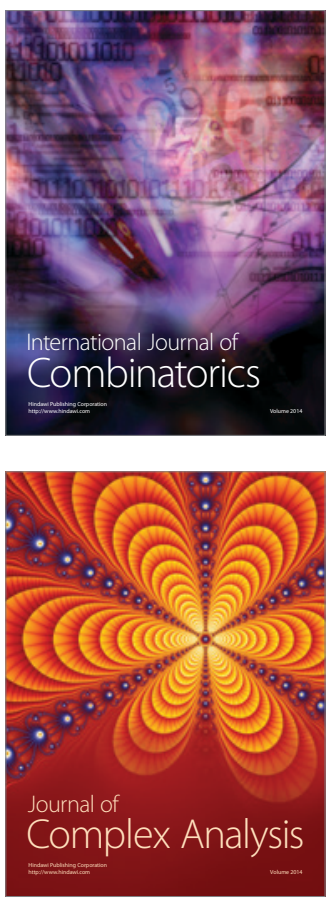

International Journal of

Mathematics and

Mathematical

Sciences
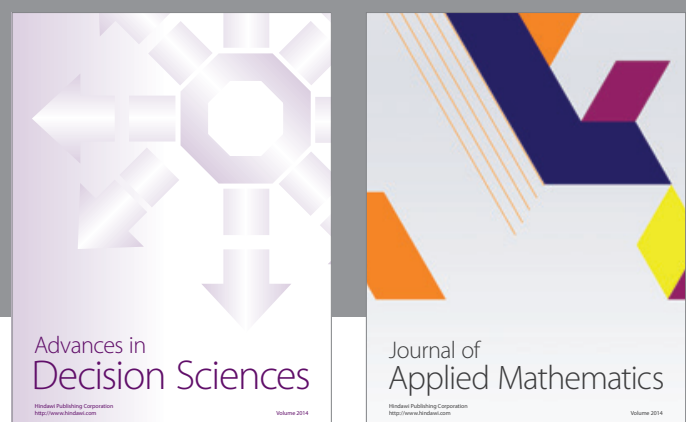

Journal of

Applied Mathematics
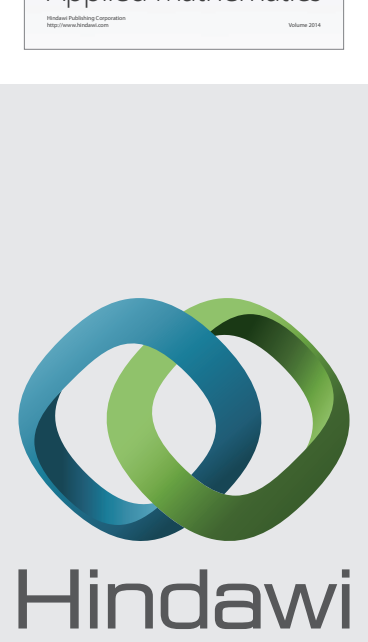

Submit your manuscripts at http://www.hindawi.com
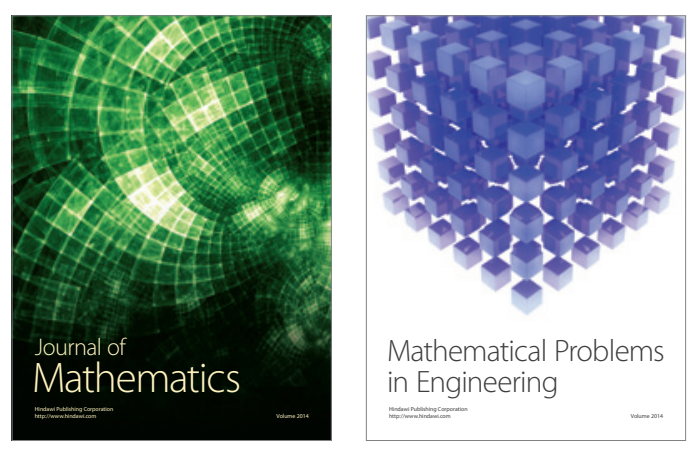

Mathematical Problems in Engineering
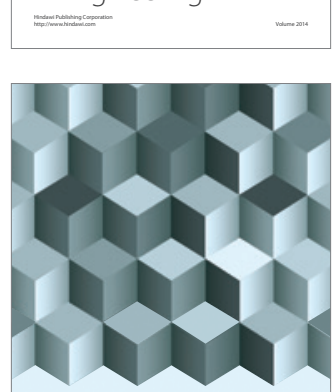

Journal of

Function Spaces
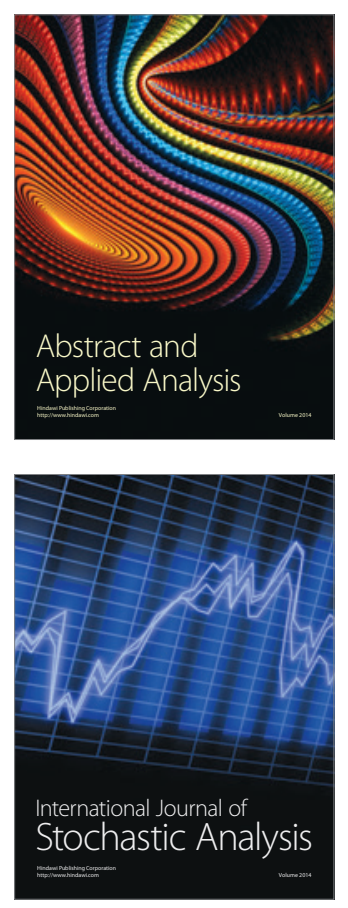

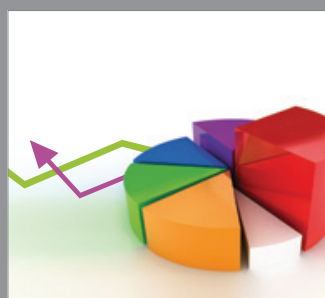

ournal of

Probability and Statistics

Promensencen
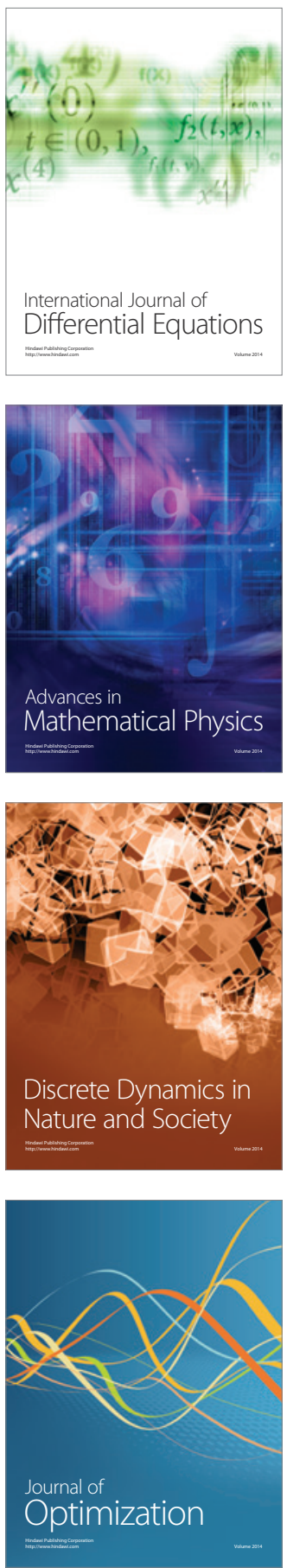